\title{
Appraisals, emotions and emotion regulation: An integrative approach
}

\author{
Susanna Schmidt $\cdot$ Carla Tinti $\cdot$ Linda J. Levine • \\ Silvia Testa
}

Published online: 25 February 2010

(c) The Author(s) 2010. This article is published with open access at Springerlink.com

\begin{abstract}
The present work aims to investigate the relation between appraisals, emotions, and emotion regulation strategies by creating a structural equation model which integrates these three aspects of the emotion process. To reach this aim, Italian students $(N=610)$ confronted with their high school diploma examination completed a questionnaire 3 weeks before the beginning of the exam. Results showed that they experienced primarily three types of emotions-anxiety/fear, frustration/powerlessness, positive emotions-which were related to specific appraisal profiles. Importantly, these appraisal profiles and emotions were associated with the use of different strategies for regulating emotions: anxiety/fear was associated with focusing on the exam, drug use, and an inability to distance oneself from the exam; frustration/powerlessness, with use of suppression, distancing, and drugs; positive emotion, with reappraisal and problem focused strategies. The effectiveness of these different strategies will be discussed.
\end{abstract}

Keywords Appraisal · Emotions ·

Emotion regulation strategies

\section{Introduction}

June in Italy: summer and holidays are approaching, but for thousands of youths, the final exam of high school is also at the door. How do they appraise this event? What emotions

S. Schmidt $(\square) \cdot$ C. Tinti $\cdot$ S. Testa

University of Turin, Turin, Italy

e-mail: susanne.schmidt@unito.it

L. J. Levine

University of California, Irvine, CA, USA do they feel? And what strategies do they use to regulate their emotions? Studies on school examination situations have sometimes focused on the relation between appraisal and emotions (Smith and Ellsworth 1985, 1987; Smith and Lazarus 1993; Smith et al. 1993), other times on the relation between emotions and the strategies used to cope with them (Folkman and Lazarus 1985; Spangler et al. 2002). In this work, possible links between all three of these aspects of emotional experience were explored.

According to appraisal theorists (e.g. Roseman 1984; Scherer 1984; Smith and Ellsworth 1985), emotions are elicited when a person evaluates an event or situation as important for his or her well-being and central concerns. Furthermore, they hold that the quality and intensity of the elicited emotion will not depend upon the situation itself, but upon the person's subjective evaluation of the situation in terms of a set of appraisal dimensions. This hypothesis is supported by several empirical findings obtained in naturally occurring situations (e.g. Folkman and Lazarus 1985; Levine 1996; Smith and Ellsworth 1987) and in laboratory studies (e.g. Ellsworth and Smith 1988; Scherer 1993; Smith and Lazarus 1993). In a recent experimental study, Siemer et al. (2007) created an ambiguous situation, which provoked different emotional reactions across participants. Participants' differing reactions could be predicted by their specific appraisal profiles, leading the authors to the conclusion that "appraisals may be necessary and sufficient to determine different emotional reactions towards a particular situation" (p. 592). This conclusion constitutes the core postulate of appraisal theories despite differences between specific models.

Moreover, among appraisal theorists there is general consensus on a standard set of necessary dimensions presumed to underlie the appraisal process: as an event unfolds, the individual concerned evaluates its significance on a number of criteria such as its importance and consequences 
for one's well-being, whether it is conducive for or obstructs one's plans and goals, and the ability to cope with the event and its consequences (e.g. Roseman and Smith 2001; Sander et al. 2005). These basic appraisals were also postulated in the pioneering work of Lazarus (1966) to explain the emotions resulting from the transaction between the person and his/her environment in stressful situations. Specifically, Lazarus held that, when people experience an event, they evaluate whether it is benign, threatening, or irrelevant for their well-being (primary appraisal) and whether they have the resources necessary to cope with the event (secondary appraisal). Primary appraisal is principally related to the intensity and valence of emotion, whereas the estimated coping potential is fundamental in further emotion differentiation (Lazarus 1991).

The major function of coping potential appraisal is indeed to determine the appropriate response to an event by evaluating the resources at one's disposal. According to Folkman and Lazarus' (1988) model of stress and coping, once the appraisal process generates emotion, coping strategies are engaged to change the person-environment relationship either by adopting strategies to regulate distressing emotions (emotion-focused coping) or by adopting strategies to change the problem causing the distress (problemfocused coping). Apart from the fact that some of these strategies focus more on the problem and others more on the elicited emotions, they all function to influence felt emotion and in this vein they resemble the more recent concept of "emotion regulation", which refers to the "strategies we use to increase, maintain, or decrease one or more components of an emotional response" (Gross 2001, p. 215).

Different emotion regulation strategies have been distinguished (Gross 1998; Parkinson et al. 1996; Thayer et al. 1994; Walden and Smith 1997). Gross (1998), in particular, proposes five sets of strategies: (1) Situation selection, which consists of approaching or avoiding people, places, or objects in order to regulate emotions; (2) Situation modification, which aims at changing the situation so as to alter its emotional impact; (3) Attentional deployment, which includes strategies like distraction and rumination; (4) Cognitive change, entailing strategies such as reappraisal which transforms the initial appraisal of the event; and (5) Response-focused strategies, which aim at influencing physiological, experiential, or behavioural aspects of the emotional response. The first four sets of strategies are antecedent-focused in that they are used before the emotion response is completely activated, whereas the fifth set is used to modulate the aspects of the fully developed emotional response. Gross (2001) hypothesizes that "adjustments made early in the emotion trajectory are more effective than adjustments made later on" (p. 218). Empirical evidence indeed shows that reappraisal and distraction are more effective than expressive suppression in down-regulating emotions (Gross 2001; Richards and Gross 2000, 2006). Gross (2001) points to the need for further research to explore the effectiveness of other antecedent- and response-focused strategies.

To sum up, appraisal theories hypothesize a causal link between specific appraisals and specific emotions. Further, the stress and coping model of Folkman and Lazarus (1988) holds that people cope with stressful situations and the elicited emotions principally by using two different kinds of strategies: problem-focused or emotion-focused. Finally, Gross (2001) more deeply investigates the different strategies people use to regulate their emotions and suggests that some strategies may be more effective than others. Little research has examined the links among appraisals, specific emotions, and the strategies chosen to regulate emotion, however (Gross and John 2003). Moreover, as noted above, the efficacy of a broader range of antecedent- and responsefocused strategies remains to be explored.

The current study investigated the links between appraisal, emotions, and regulation strategies by building a structural equation model which integrates a model of the emotions evoked by differing appraisals of stressful circumstances (Folkman and Lazarus 1988) with a model of antecedent- versus response-focused strategies for regulating emotions (Gross 1998). We hypothesized that the appraisal process generates and shapes the intensity and quality of emotion, and that both, appraisal and the resulting emotions, influence the selection of emotion regulation strategies. In other words, specific evaluations should be associated to specific emotions which, in turn, because they arise from this specific appraisal profile, should enhance the preference for one rather than another emotion regulation strategy. Based on this assumption, we expected that the strategies people adopt to regulate emotions do depend on the particular emotion they are trying to regulate, for instance, people may use different strategies when attempting to regulate feelings of frustration versus fear.

To test these hypotheses, the current investigation examined the relations among the appraisals, emotions and emotion regulation strategies of youths preparing for their high school final examination. The choice of this situation allowed us to combine some of the advantages of laboratory and field research. As in laboratory studies, all students were responding to the same situation, their pending exam; however, as in field research, the situation was a stressful real-life event with an uncertain outcome and great personal relevance. Based on the empirical findings reviewed above, we hypothesized that students who appraised the exam as important, and their coping potential as high, would experience more positive emotions such as hope and challenge, and in turn, adopt more effective, antecedent-focused strategies for regulating emotion such as studying and positive reappraisal. In contrast, we hypothesized that 
students who appraised the exam as important, but evaluated their coping potential as low, would feel more negative emotions such as anxiety, fear, and frustration, and adopt less-effective, response-focused strategies such as expressive suppression or drug use.

\section{Method}

This study was part of a larger research project which involved data collection at three points in time: before, between and after the written and oral parts of the final examination. Data were collected at each time point using questionnaires. The present study concerns the appraisals, emotions, and emotion regulation strategies that students reported 3 weeks before their exam.

\section{Participants}

Participants were 610 Italian students in their final year of high school. Their ages ranged from 18 to 23 years $(M=18.7$ years, $\mathrm{SD}=0.9)$ and $28 \%$ were males.
Measures

\section{Appraisals}

Eighteen questions, based on existing appraisal questionnaires (e.g. Smith and Ellsworth 1985; Smith and Lazarus 1993; Scherer 1993), assessed the following aspects of students' appraisals of their high school exit examination: the importance or consequentiality of the event, its goal congruence/incongruence, their coping potential, and their causal attributions. The appraisal questions are listed in Table 1. Students responded to appraisal questions (e.g. "How important is this event to you?") using 11-point scales ranging from 0 (not at all) to 10 (extremely).

\section{Emotions}

Students rated the intensity with which they felt each of 18 emotions using 11-point scales that ranged from 0 (not at all) to 10 (extremely). The emotions assessed are listed in Table 2. The emotions selected were based on Smith and Ellsworth's (1987) findings concerning the emotions students felt when taking an exam.

Table 1 Appraisals: standardized loadings and error variances of the measurement model and descriptive statistics

\begin{tabular}{|c|c|c|c|c|c|c|}
\hline Appraisal & Importance & Coping potential & External control & Error variance & $M$ & SD \\
\hline Personal importance & $0.80 *$ & - & - & 0.36 & 7.32 & 2.49 \\
\hline Centrality $^{\mathrm{a}}$ & $0.65^{*}$ & - & - & 0.58 & 7.15 & 2.21 \\
\hline Goal conduciveness & $0.65^{*}$ & - & - & 0.57 & 6.39 & 2.71 \\
\hline Consequentiality & $0.59 *$ & - & - & 0.65 & 5.76 & 2.95 \\
\hline Thinking about $^{\mathrm{a}}$ & $0.57 *$ & - & - & 0.68 & 6.80 & 2.08 \\
\hline Effort & $0.50 *$ & - & - & 0.75 & 8.58 & 1.46 \\
\hline Importance for parents & $0.46^{*}$ & - & - & 0.79 & 7.60 & 2.37 \\
\hline Ability to give the best & - & $0.81 *$ & - & 0.34 & 6.39 & 2.00 \\
\hline Preparedness & - & $0.68 *$ & - & 0.54 & 5.35 & 2.13 \\
\hline Outcome probability & - & $0.55^{*}$ & - & 0.70 & 5.42 & 2.32 \\
\hline Pleasantness & - & $0.53 *$ & - & 0.72 & 5.21 & 2.40 \\
\hline Engagement ${ }^{\mathrm{b}, \mathrm{c}}$ & - & $0.40 *$ & - & 0.84 & 8.44 & 1.64 \\
\hline Ability to control emotions & - & $0.38 *$ & - & 0.86 & 4.43 & 2.69 \\
\hline Certainty about how the exam would unfold & - & $0.37 *$ & - & 0.86 & 5.93 & 2.35 \\
\hline Ability $^{\mathrm{b}, \mathrm{c}}$ & - & $0.33 *$ & - & 0.89 & 8.54 & 1.63 \\
\hline Professors $^{\mathrm{c}}$ & - & - & $0.66^{*}$ & 0.57 & 7.62 & 2.11 \\
\hline Difficulty of exam ${ }^{c}$ & - & - & $0.56^{*}$ & 0.68 & 8.06 & 1.74 \\
\hline Chance $^{\mathrm{c}}$ & - & - & $0.53 *$ & 0.72 & 5.99 & 2.68 \\
\hline
\end{tabular}

$* p<0.05$

a,b Due to the semantic similarity between the appraisals "Centrality" and "Thinking about," and the similar wording of the questions related to the appraisals of "Engagement" and "Ability," the errors between these pairs of items were allowed to be correlated (

$\mathrm{b}$ error correlation $=0.37$ )

c These items measured accountability for the unfolding and outcome of the exam 
Table 2 Emotions: standardized loadings and error variances of the measurement model and descriptive statistics

\begin{tabular}{|c|c|c|c|c|c|c|}
\hline Emotion & Frustration/powerlessness & Positive emotion & Anxiety/fear & Error variance & $M$ & SD \\
\hline Helplessness & $0.67 *$ & - & - & 0.56 & 2.73 & 3.07 \\
\hline Frustration & $0.65 *$ & - & - & 0.58 & 3.80 & 3.51 \\
\hline Sadness & $0.63 *$ & - & - & 0.60 & 3.79 & 3.20 \\
\hline Anger & $0.60 *$ & - & - & 0.64 & 2.89 & 3.03 \\
\hline Guilt & $0.53 *$ & - & - & 0.72 & 2.01 & 2.86 \\
\hline Shame & $0.51 *$ & - & - & 0.74 & 3.26 & 3.23 \\
\hline Disgust $^{\mathrm{c}}$ & $0.49 *$ & - & - & 0.76 & 0.38 & 0.49 \\
\hline Curiosity $^{\mathrm{a}}$ & - & $0.70 *$ & - & 0.51 & 4.69 & 2.97 \\
\hline Interest $^{\mathrm{a}}$ & - & $0.65^{*}$ & - & 0.58 & 5.26 & 2.80 \\
\hline Happiness & - & $0.61 *$ & - & 0.62 & 2.80 & 2.60 \\
\hline Surprise & - & $0.56^{*}$ & - & 0.68 & 2.70 & 2.65 \\
\hline Challenge $^{\mathrm{b}}$ & - & $0.47 *$ & - & 0.78 & 5.86 & 3.29 \\
\hline Pride $^{\mathrm{b}}$ & - & $0.41 *$ & - & 0.83 & 4.01 & 3.36 \\
\hline Hope & - & $0.40 *$ & - & 0.84 & 7.48 & 2.60 \\
\hline Relief & - & $0.39 *$ & - & 0.85 & 4.68 & 3.77 \\
\hline Fear & - & - & $0.90 *$ & 0.19 & 7.49 & 2.53 \\
\hline Anxiety & - & - & $0.80^{*}$ & 0.36 & 7.74 & 2.56 \\
\hline Boredom & $0.47 *$ & - & $-0.56^{*}$ & 0.72 & 1.82 & 2.46 \\
\hline
\end{tabular}

$* p<0.05$

a,b Due to the semantic similarity between "Curiosity" and "Interest," and between "Challenge" and "Pride," the errors between these two pairs of emotions were allowed to be correlated ( ${ }^{\mathrm{a}}$ error correlation $=0.18{ }^{\mathrm{b}}$ error correlation $=0.23$ )

${ }^{c}$ Disgust ratings were dichotomized

\section{Emotion regulation strategies}

The strategies students used to cope with the imminent exam and their emotions were assessed using 18 questions. The questions were selected from existing questionnaires (COPE, Carver et al. 1989; Brief COPE, Carver 1997; revised Ways of Coping, Folkman et al. 1986; Emotion Regulation, Gross and John 2003), and adapted with the aim of assessing the following types of strategies: problemfocused strategies (e.g. I focus only on studying), suppression (e.g. I try to suppress my feelings), social support (e.g. I discuss the exam with friends), positive reappraisal (e.g. I try to see the positive aspects of this experience), distancing/distraction (e.g. I try to not think about the exam), avoidance (e.g. I take drugs to relax). Students rated the extent to which they were using each strategy on 11point scales that ranged from 0 (not at all) to 10 (extremely). The emotion regulation strategies assessed are listed in Table 3.

Procedure

Three weeks before the beginning of the exam, a questionnaire was distributed by trained staff in 8 high schools in Turin and in 9 high schools in Florence. After receiving permission from school directors and teachers, a member of the research staff entered in the classroom during school time, explained the purpose of the study, and distributed the questionnaire to those students who agreed to participate $(97 \%)$. On average, the questionnaire took $15 \mathrm{~min}$ to complete. Participants were informed that the questionnaire was anonymous and that data would be used only for research purposes.

Data analysis

Data analysis was conducted in three steps: (1) descriptive analyses, (2) measurement models of appraisal, emotions, and emotion regulation strategies, (3) creation of a structural equation model to explore the relations among appraisals, emotions, and regulation strategies.

\section{Results}

Descriptive results

Mean ratings and standard deviations for students' appraisals concerning their upcoming high school exit exam are shown in the last two columns of Table 1. 
Table 3 Emotion regulation: standardized loadings and error variances of the measurement model and descriptive statistics

\begin{tabular}{|c|c|c|c|c|c|c|c|c|c|}
\hline Regulation strategy & Suppression & Reappraisal & $\begin{array}{l}\text { Social } \\
\text { support }\end{array}$ & $\begin{array}{l}\text { Problem } \\
\text { focused }\end{array}$ & Distancing & Drugs & $\begin{array}{l}\text { Error } \\
\text { variance }\end{array}$ & $M$ & SD \\
\hline I try to suppress my emotions & $0.80^{*}$ & - & - & - & - & - & 0.37 & 2.16 & 2.61 \\
\hline I try not to show my feelings & $0.63 *$ & - & - & - & - & - & 0.60 & 3.76 & 3.09 \\
\hline I withdraw and isolate myself & $0.57 *$ & - & - & - & - & - & 0.67 & 2.08 & 2.74 \\
\hline I try to learn from the experience & - & $0.87 *$ & - & - & - & - & 0.25 & 5.90 & 2.85 \\
\hline $\begin{array}{l}\text { I try to see positive aspects of the } \\
\text { experience }\end{array}$ & - & $0.84^{*}$ & - & - & - & - & 0.29 & 5.21 & 2.90 \\
\hline I seek emotional support & - & - & $0.69 *$ & - & - & - & 0.53 & 5.44 & 3.09 \\
\hline I let my feelings out & - & - & $0.55^{*}$ & - & - & - & 0.70 & 4.72 & 2.82 \\
\hline I discuss the exam with friends & - & - & $0.46^{*}$ & - & - & - & 0.79 & 5.78 & 2.64 \\
\hline I practice relaxation techniques & - & - & $0.28 *$ & - & - & - & 0.92 & 1.51 & 2.48 \\
\hline I pray or go to church $^{\mathrm{a}}$ & - & - & $0.27 *$ & - & - & - & 0.93 & 0.30 & 0.46 \\
\hline I focus only on studying & - & - & - & $0.75^{*}$ & - & - & 0.43 & 4.50 & 2.74 \\
\hline I think only about the exam & - & - & - & $0.71 *$ & - & - & 0.49 & 3.17 & 2.82 \\
\hline I engage in fun activities & - & - & - & - & $0.57 *$ & - & 0.67 & 5.68 & 2.90 \\
\hline I make fun of or minimize the exam & - & - & - & - & $0.52 *$ & - & 0.73 & 3.93 & 3.18 \\
\hline I try to make my mind off it & - & - & - & - & $0.47 *$ & - & 0.78 & 4.57 & 3.11 \\
\hline I think it is useless to do anything & - & - & - & - & $0.13^{*}$ & - & 0.98 & 1.87 & 2.70 \\
\hline I take drugs to relax ${ }^{a}$ & - & - & - & - & - & $0.89 *$ & 0.21 & 0.14 & 0.35 \\
\hline I take drugs to concentrate ${ }^{\mathrm{a}}$ & - & - & - & - & - & $0.59 *$ & 0.65 & 0.18 & 0.38 \\
\hline
\end{tabular}

$* p<0.05$

" Ratings for the following strategies were dichotomized: "I pray/go to church", "I take drugs to relax", "I take drugs to concentrate"

Students appraised the exam as an important event for both themselves and their parents. They rated the exam as occupying a central place in their lives and in their thoughts, as requiring a lot of effort, and as very consequential and relevant to their goals. Furthermore, students were highly confident of their ability to put forth their best effort, despite feeling only moderately prepared and able to control their emotions, and only moderately sure about the outcome and about how the exam would unfold. Students expected the outcome of the exam to depend primarily on their ability and effort, and, to a lesser extent, on the difficulty of the exam, the professors, and chance.

Mean ratings and standard deviations of students' emotions concerning their upcoming exam are shown in the last two columns of Table 2 . The emotions students felt most intensely were anxiety, fear, and hope, followed by challenge, interest, curiosity, relief and pride. At lower intensities, students also reported feeling frustration, sadness, shame/embarrassment, anger, happiness, helplessness and surprise. Finally, guilt, boredom and disgust were reported only at very low intensity levels.

Mean ratings and standard deviations of the extent to which students used different strategies to cope with the imminent exam and regulate their emotions are shown in the last two columns of Table 3 . The strategies that students reported using most were trying to learn from the experience, trying to see positive aspects of the experience, discussing the exam with friends, expressing their feelings, and engaging in fun activities. To a lesser degree, students also reported focusing only on studying and thinking only of the exam, or conversely, distancing themselves from the exam or their feelings by taking their mind off the exam, minimizing the exam, not showing or suppressing their emotions, and isolating themselves. Regulation strategies used very little included deciding that it was futile to do anything, using relaxation techniques, praying, and using drugs to relax or concentrate.

Measurement models of appraisals, emotions and emotion regulation

Exploratory factor analyses were performed on students' ratings of their appraisals, emotions, and emotion regulation strategies. Alternative possible solutions were analysed and interpreted according to the theoretical hypotheses and the empirical findings presented in the introduction. The most plausible solutions were then tested using LISREL 8.7 (Jöreskog and Sörbom 2005). Since variables were not multinormal-Mardia's test with Prelis, $\chi^{2}(2, N=610)=$ 2917.98, $p<0.001$ - we used the Robust Maximum Likelihood method (MLR) for estimation. A model generation approach was taken (MacCallum 1995). Based on 
Modification Index values and theoretical considerations, we modified the measurement models until we arrived at solutions that produced adequate fit index values evaluated by SRMR (Standardized Root Mean Square Residual), CFI (Comparative Fit Index), and RMSEA (Root Mean Square Error of Approximation). We deemed the measurement models acceptable if SRMR was less than or equal to 0.10, CFI was equal to 0.90 or greater, and RMSEA was equal to 0.08 or less (Browne and Cudeck 1993; Hu and Bentler 1995).

\section{Appraisal}

Standardized loadings and error variance for the model of appraisal are shown in Table 1. We retained as acceptable a model with three latent variables labelled importance, coping potential, and external control $\left(\chi^{2}(130, \quad N=\right.$ $610)=557.55, p<0.001 ;$ SRMR $=0.088 ;$ RMSEA $=$ 0.073 ; $\mathrm{CFI}=0.92$ ). All standardized loadings were greater than 0.30 and statistically significant $(p<0.05)$. The first latent variable was composed of items referring to the relevance/consequentiality of the exam; the second latent variable, labeled coping potential, was composed of items referring to subjective expectations concerning the capacity to cope with the exam; finally, the third factor, labeled external control, was composed of items referring to external causes of the outcome of the exam (professors, task difficulty, chance). All the relations among the latent variables were statistically significant $(p<0.05)$. Importance was positively correlated with coping potential $(r=0.53)$ and external control $(r=0.27)$; coping potential was negatively associated with external control $(r=-0.13)$.

\section{Emotion}

Standardized loadings and error variance for the model of emotion are shown in Table 2. We retained as acceptable a model with three latent variables labelled frustration/powerlessness, anxiety/fear, and positive emotion $\left(\chi^{2}(129, N=\right.$ $610)=600.05, p<0.001 ;$ SRMR $=0.079 ;$ RMSEA $=$ 0.077; CFI $=0.90$ ). All standardized loadings were greater than 0.35 and statistically significant $(p<0.05)$. Positive emotions formed a single factor in which curiosity, interest and happiness were the items with the highest saturations; negative emotions loaded on a second factor, with the exception of anxiety and fear that loaded on a third factor, and boredom that loaded on both negative emotions factors. With respect to the relations among the latent variables, anxiety/fear was positively correlated $(p<0.05)$ with frustration/powerlessness $(r=0.47)$ and positive emotion $(r=0.21)$; the correlation between frustration/powerlessness and positive emotion did not differ significantly from zero.

\section{Emotion regulation}

Finally, standardized loadings and error variance for the model of emotion regulation strategies are shown in Table 3. We retained a model with the following six latent variables: suppression, reappraisal, social support, distancing, problem-focused strategies, and drug use $\left(\chi^{2}(120, N=\right.$ $610)=320.34, p<0.001 ;$ SRMR $=0.056$; RMSEA $=$ 0.052 ; $\mathrm{CFI}=0.92$ ). All standardized loadings were statistically significant $(p<0.05)$. Three items loaded poorly on their latent variables: "practice of relaxation techniques" and "praying or going to Church" on the social support factor and "thinking it is useless to do anything" on the distancing factor. We decided not to remove them from the model because they enrich the meaning of the factors they load on even if their contribution is very low. With respect to the associations among the latent variables, social support was positively correlated $(p<0.05)$ with problemfocused strategies $(r=0.48)$, reappraisal $(r=0.38)$, suppression $(r=0.18)$, distancing $(r=0.15)$ and drug use $(r=0.29)$. Problem focused strategies were negatively associated with distancing $(r=-0.47)$ and positively associated with reappraisal $(r=0.29)$, suppression $(r=0.28)$, and drug use $(r=0.24)$. Finally, suppression was positively associated with distancing $(r=0.19)$ and drug use $(r=0.21)$. The remaining correlations did not differ significantly from zero.

Relations between appraisals, emotions, and emotion regulation

To evaluate the possible links among appraisals, emotions, and emotion regulation, we tested a model in which each latent dimension of appraisal was linked to each of the three latent emotions, which in turn were linked to each of the six regulation strategies (Fig. 1). This global model had the following fit indexes: $\chi^{2}(1342, \quad N=610)=3880.71, \quad p<0.001$; SRMR $=0.078 ;$ RMSEA $=0.056 ; \mathrm{CFI}=0.90{ }^{1}$

Figure 1 shows that emotions were related to different appraisal profiles. Anxiety/fear was associated with evaluating the exam as important and coping potential as low. Frustration/powerlessness was associated with evaluating the exam as important, the outcome as dependent on external factors, and coping potential as low. Positive emotion was associated with evaluating the exam as

\footnotetext{
${ }^{1}$ Following the suggestion of the reviewers, we also specified an equivalent model (MacCallum et al. 1993), in which the paths between emotions and emotion regulation were reversed (i.e. a model in which emotions were influenced by emotion regulation strategies). This model showed poorer fit values: $\chi^{2}(1342, N=610)=4547.10$, $p<0.001 ;$ SRMR $=0.11 ;$ RMSEA $=0.063 ;$ CFI $=0.88$.
} 
Fig. 1 Standardized model parameters. The figure displays only significant relations $(p<0.05)$, although all possible paths from appraisal to emotion and from emotion to regulation strategies were tested in the model

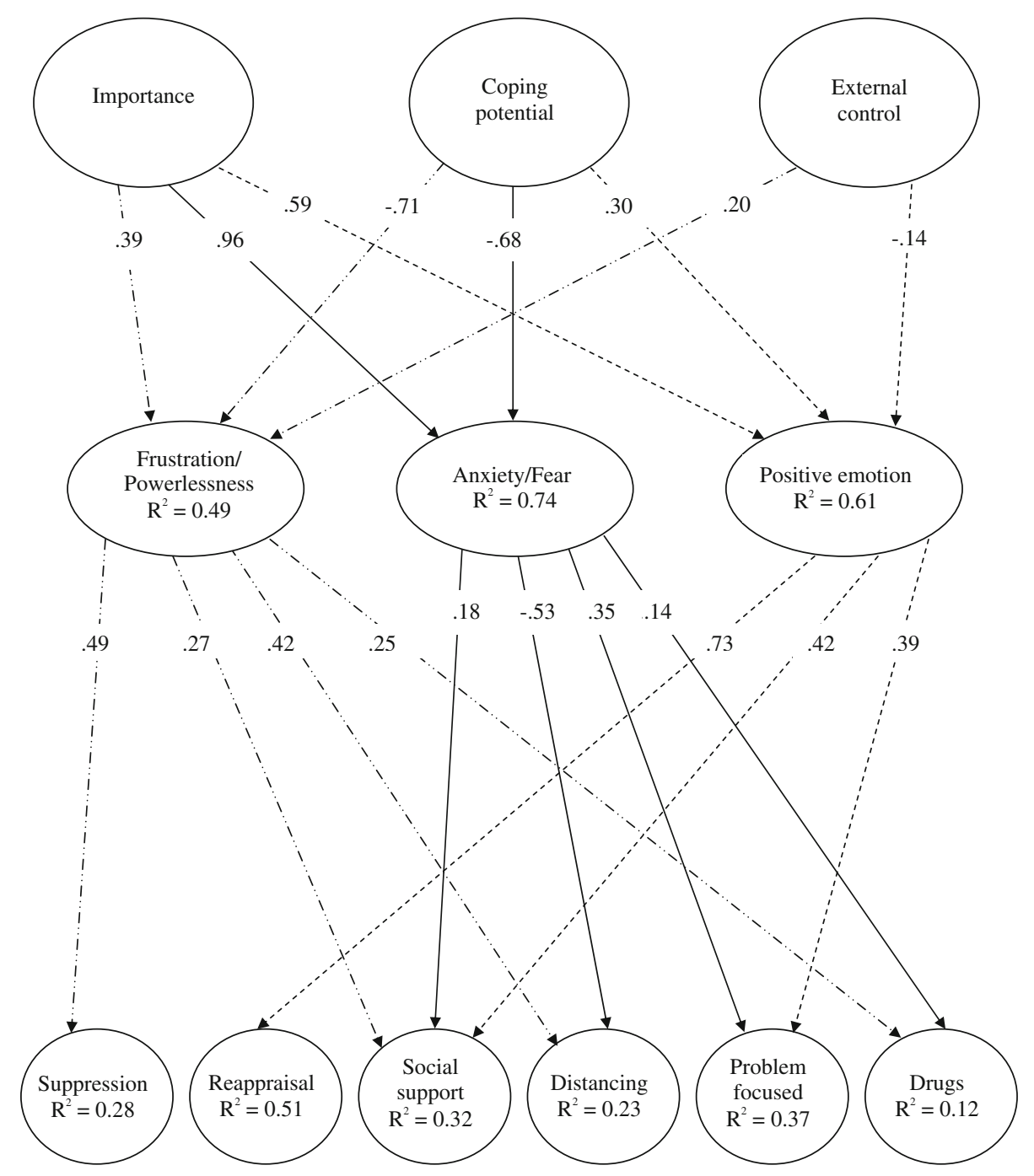

important, coping potential as high, and external control as low. The $R^{2}$ values (shown in the ellipses in Fig. 1) provide a measure of the latent variable equation fit, and indicate that the appraisal dimensions explain much of the variance of the emotion latent variables, especially in the case of anxiety/fear $\left(R^{2}=0.74\right)$.

Figure 1 also shows that the three latent emotions are associated with different regulation strategies. Frustration/ powerlessness was positively associated with suppressing emotion, distancing, and drug use. Anxiety/fear was positively associated with problem-focused strategies and drug use, but negatively associated with distancing. Positive emotion was associated with reappraisal and problemfocused strategies. Finally, each of the three latent emotion variables was positively associated with seeking social support. As indicated by the $R^{2}$ values, the explained variances of the single strategies were rather heterogeneous ranging from a maximum of 0.51 for reappraisal to a minimum of 0.12 for drug use.

\section{Discussion}

Based on the theoretical models of Folkman and Lazarus (1988) and Gross (1998), the present work investigated the relations among appraisals, emotions, and emotion regulation by creating a structural equation model, derived from empirical data, which integrated the two models. In particular, the appraisals, emotions, and emotion regulation strategies of adolescents preparing for their high school final exam were assessed. Results indicated that students in this situation experienced primarily three types of emotions: frustration/powerlessness, anxiety/fear, and positive emotion. Consistent with appraisal theories, these emotions were related to different appraisal profiles: anxiety/fear seemed to arise when students evaluated the exam as important and their ability to cope with it as low. Feelings of frustration/powerlessness seemed to arise when students evaluated the exam as important, their ability to cope with it as low, and the outcome as dependent on external, 
uncontrollable factors. Finally, positive emotion seemed to arise when students evaluated the exam as important, their ability to cope with it as high, and the outcome as not dependent on external, uncontrollable factors.

As predicted, the emotion regulation strategies students reported using were related to the type of emotion they were experiencing. The more students experienced anxiety/fear, the more they reported focusing on the exam, using drugs, and not being able to distance themselves from the exam. The more students reported feeling frustration/powerlessness, the more they reported using suppression, distancing, and drugs. The more students reported feeling positive emotions, the more they reported engaging in reappraisal and problem-focused strategies. Finally, seeking social support was an important strategy in this stressful situation irrespective of how the exam was appraised and the emotions it evoked.

Past research on emotion regulation has focused primarily on how specific emotion regulation strategies affect the intensity of emotion, physiological responding, and cognitive processes such as memory. Comparatively little research has examined the links between specific emotions and specific strategies for regulating those emotions. Drawing on Gross's (1998) distinction between antecedent- and response-focused strategies, we found that students who felt more frustration/powerlessness reported greater use of response-focused strategies such as emotion suppression, distancing, and drug use. Thus, the more students evaluated their coping potential as low and the exam outcome as dependent on external causes, the more they experienced frustration/powerlessness, and adopted strategies by which they attempted to modify their emotional experience or expression rather than the situation itself or their appraisals of it. Such strategies, at least in the long term, are probably not very adaptive. In contrast, the experience of anxiety/fear was associated with problem-focused strategies and a decrease in distancing, though it was also positively related to drug use. The attempt to face the problem, in this case by studying, could probably be considered an adaptive strategy. However, anxiety/fear may also make it impossible to take one's mind off the stressful situation and accompanying emotions (cf. rumination as defined by Gross 1998; Ray et al. 2008), increasing the need to modify the emotional response with drugs. This regulation process could be quite ineffective in producing positive outcomes from the stressful encounter.

The relations observed between positive emotions, appraisals, and emotion regulation strategies were of particular interest for several reasons. First, most studies in the stress and coping literature have been carried out to understand how people regulate negative emotions as a way to cope with negative events (e.g. Gross 2002; Lazarus and Alfert 1964; Schartau et al. 2009). Relatively little attention has been paid to the regulation of positive emotions (but see Gross 2001; Folkman and Moskowitz 2000; Tugade and Fredrickson 2007). Second, it seems that positive emotions lead to strategies that do not necessarily down-regulate emotions but rather promote behaviors and cognitions that maintain positive emotion (Gross 2001). Moreover, people also engage in strategies that increase their positive emotional experience (Tugade and Fredrickson 2007; Wegener and Petty 1994) and these kinds of regulation strategies seem to be important, not only in positive situations, but especially in the negative ones. For example, Folkman and Moskowitz (2000), in their study on the wellbeing of caregivers of partners with AIDS, found that regulation strategies that sustain positive emotions help buffer against stress.

The assumption that positive emotions could be particularly functional when facing negative emotional circumstances is supported by the broaden-and-build theory of positive emotions, proposed by Fredrickson (1998; 2001). This theory posits that positive emotions broaden an individual's thought-action repertoire, which, in turn, has the effect of enlarging his or her physical, intellectual and social resources. Specifically, positive emotions are thought to produce patterns of thought and action that enhance creative, flexible and efficient problem-solving (Isen 2001; Isen et al. 1987) and, at the same time, are useful in building important and enduring personal resources (Fredrickson 2001). In this sense, emotion regulation can have a short-term and a long-term effect on well-being.

The current investigation revealed that students who experienced greater positive emotion concentrated more on the antecedent-focused strategies of studying, which was adaptive under the circumstances, and reappraisal, which is associated with enhanced wellbeing (Gross and John 2003). Although the causal direction of these associations cannot be determined from this study, it may be important to encourage positive affect in adolescents facing stressful events such as final examinations. But how might they be encouraged to face such stressful events with positive emotions? Based upon our results, we suggest that it is important to encourage the appraisal that attaining successful outcomes depends on their own resources, thus enhancing the probability that they will face future problems with efficient strategies. This might be accomplished, for example, by offering children the opportunity to face tasks which are neither too easy nor too difficult (i.e. "optimal challenges", Harter 1978) throughout their school career, allowing them to enhance their sense of self-efficacy (Bandura 1977). 


\section{Conclusion}

Emotions are products of how people appraise their ongoing transactions with the environment. In this sense, emotions are of tremendous diagnostic value, because their intensity and quality reveal how people think they are managing what is important to them in a particular context. Moreover, when an individual evaluates an event or a situation as offering important challenges or opportunities, emotional response tendencies are generated (Buck 1994; Frijda 1986; Scherer 1984). Importantly, though, these emotional response tendencies are often altered, and the ways in which they are altered determine the intensity and quality of the final emotional response (Gross 1998). Starting from these premises, in the present work, a structural equation model was built that made it possible to integrate the theoretical models of Folkman and Lazarus (1988) and Gross (1998). This model suggests that specific emotions depend upon specific appraisal profiles, and in turn, promote the selection of specific regulation strategies. Because the cross-sectional design of the current study does not allow one to definitely determine the direction of the causal relations among appraisal, emotion and emotion regulation, further research is needed to confirm the proposed model as well as to determine if it holds for other stressful situations.

Open Access This article is distributed under the terms of the Creative Commons Attribution Noncommercial License which permits any noncommercial use, distribution, and reproduction in any medium, provided the original author(s) and source are credited.

\section{References}

Bandura, A. (1977). Self-efficacy: Toward a unifying theory of behavioral change. Psychological Review, 84, 191-215.

Browne, M. W., \& Cudeck, R. (1993). Alternative ways of assessing fit. In K. A. Bollen \& J. S. Long (Eds.), Testing structural equation models (pp. 136-162). Newbury Park, CA: Sage.

Buck, R. (1994). Social and emotional functions in facial expression and communication: The readout hypothesis. Biological Psychology, 38, 95-115.

Carver, C. S. (1997). You want to measure coping but your protocol's too long: Consider the brief COPE. International Journal of Behavioral Medicine, 4, 92-100.

Carver, C. S., Scheier, M. F., \& Weintraub, J. K. (1989). Assessing coping strategies: A theoretically based approach. Journal of Personality and Social Psychology, 56, 267-283.

Ellsworth, P. C., \& Smith, C. A. (1988). Shades of joy: Patterns of appraisal differentiating pleasant emotions. Cognition \& Emotion, 2, 301-331.

Folkman, S., \& Lazarus, R. S. (1985). If it changes it must be a process: Study of emotion and coping during three stages of a college examination. Journal of Personality and Social Psychology, 48, 150-170.

Folkman, S., \& Lazarus, R. S. (1988). Coping as a mediator of emotion. Journal of Personality and Social Psychology, 54, 466-475.

Folkman, S., Lazarus, R. S., Dunkel-Schetter, C., DeLongis, A., \& Gruen, R. J. (1986). Dynamics of a stressful encounter:
Cognitive appraisal, coping, and encounter outcomes. Journal of Personality and Social Psychology, 50, 992-1003.

Folkman, S., \& Moskowitz, J. T. (2000). Stress, positive emotion, and coping. Current Directions in Psychological Science, 9, 115118.

Fredrickson, B. L. (1998). What good are positive emotions? Review of General Psychology, 2, 300-319.

Fredrickson, B. L. (2001). The role of positive emotions in positive psychology: The broaden-and-build theory of positive emotions. American Psychologist, 56, 218-226.

Frijda, N. H. (1986). The emotions. Cambridge, England: Cambridge University Press.

Gross, J. J. (1998). The emerging field of emotion regulation: An integrative review. Review of General Psychology, 2, 271-299.

Gross, J. J. (2001). Emotion regulation in adulthood: Timing is everything. Current Directions in Psychological Science, 10, 214-219.

Gross, J. J. (2002). Emotion regulation: Affective, cognitive, and social consequences. Psychophysiology, 39, 281-291.

Gross, J. J., \& John, O. P. (2003). Individual differences in two emotion regulation processes: Implications for affect, relationships, and well-being. Journal of Personality and Social Psychology, 85, 348-362.

Harter, S. (1978). Pleasure derived from cognitive challenge and mastery. Child Development, 45, 661-669.

Hu, L., \& Bentler, P. M. (1995). Evaluating model fit. In R. H. Hoyle (Ed.), Structural equation modeling. Concepts, issues, and applications (pp. 76-99). London: Sage.

Isen, A. M. (2001). An influence of positive affect on decision making in complex situations: Theoretical issues with practical implications. Journal of Consumer Psychology, 11, 75-85.

Isen, A. M., Daubman, K. A., \& Nowicki, G. P. (1987). Positive affect facilitates creative problem solving. Journal of Personality and Social Psychology, 52, 1122-1131.

Jöreskog, K. G., \& Sörbom, D. (2005). LISREL 8.7 for windows [computer software]. Lincolnwood, IL: Scientific Software International, Inc.

Lazarus, R. S. (1966). Psychological stress and the coping process. New York, NY: McGraw-Hill.

Lazarus, R. S. (1991). Emotion and adaptation. New York: Oxford University Press.

Lazarus, R. S., \& Alfert, E. (1964). Short-circuiting of threat by experimentally altering cognitive appraisal. Journal of Abnormal and Social Psychology, 69, 195-205.

Levine, L. J. (1996). The anatomy of disappointment: A naturalistic test of appraisal models of sadness, anger, and hope. Cognition \& Emotion, 10, 337-359.

MacCallum, R. C. (1995). Model specification: Procedures, strategies and related issues. In R. H. Hoyle (Ed.), Structural equation modeling (pp. 16-36). Thousand Oaks, CA: Sage.

MacCallum, R. C., Wegener, D. T., Uchino, B. N., \& Fabrigar, L. R. (1993). The problem of equivalent models in applications of covariance structure analysis. Psychological Bulletin, 114, 185199.

Parkinson, B., Totterdell, P., Briner, R. B., \& Reynolds, S. (1996). Changing moods: The psychology of mood and mood regulation. London: Longman.

Ray, R. D., Wilhelm, F. H., \& Gross, J. J. (2008). All in the mind's eye? Anger rumination and reappraisal. Journal of Personality and Social Psychology, 94, 133-145.

Richards, J. M., \& Gross, J. J. (2000). Emotion regulation and memory: The cognitive costs of keeping one's cool. Journal of Personality and Social Psychology, 79, 410-424.

Richards, J. M., \& Gross, J. J. (2006). Personality and emotional memory: How regulating emotion impairs memory for emotional events. Journal of Research in Personality, 40, 631-651. 
Roseman, I. J. (1984). Cognitive determinants of emotions: A structural theory. In P. Shaver (Ed.), Review of personality and social psychology (Vol. 5, pp. 11-36). Beverly Hills, CA: Sage Publications.

Roseman, I. J., \& Smith, C. A. (2001). Appraisal theory: Overview, assumptions, varieties, controversies. In K. R. Scherer, A. Schorr, \& T. Johnstone (Eds.), Appraisal processes in emotion: Theory, methods, research (pp. 3-19). New York, NY: Oxford University Press.

Sander, D., Grandjean, D., \& Scherer, K. R. (2005). A systems approach to appraisal mechanisms in emotion. Neural Networks, $18,317-352$.

Schartau, P. E. S., Dalgleish, T., \& Dunn, B. D. (2009). Seeing the bigger picture: Training in perspective broadening reduces selfreported affect and psychophysiological response to distressing films and autobiographical memories. Journal of Abnormal Psychology, 118, 15-27.

Scherer, K. R. (1984). On the nature and function of emotion: A component process approach. In K. R. Scherer \& P. E. Ekman (Eds.), Approaches to emotion (pp. 293-317). Hillsdale, NJ: Erlbaum.

Scherer, K. R. (1993). Studying the emotion-antecedent appraisal process: An expert system approach. Cognition \& Emotion, 7, 325-355.

Siemer, M., Mauss, I., \& Gross, J. J. (2007). Same situationDifferent emotions: How appraisals shape our emotions. Emotion, 7, 592-600.

Smith, C. A., \& Ellsworth, P. C. (1985). Patterns of cognitive appraisal in emotion. Journal of Personality and Social Psychology, 48, 813-838.
Smith, C. A., \& Ellsworth, P. C. (1987). Patterns of appraisal and emotion related to taking an exam. Journal of Personality and Social Psychology, 52, 475-488.

Smith, C. A., Haynes, K. N., Lazarus, R. S., \& Pope, L. K. (1993). In search of the "hot" cognitions: Attributions, appraisals, and their relation to emotion. Journal of Personality and Social Psychology, 65, 916-929.

Smith, C. A., \& Lazarus, R. S. (1993). Appraisal components, core relational themes, and the emotions. Cognition \& Emotion, 7, 233-269.

Spangler, G., Pekrun, R., Kramer, K., \& Hofmann, H. (2002). Students' emotions, physiological reactions, and coping in academic exams. Anxiety, Stress \& Coping, 15, 413-432.

Thayer, R. E., Newman, J. R., \& McClain, T. M. (1994). Selfregulation of mood: Strategies for changing a bad mood, raising energy, and reducing tension. Journal of Personality and Social Psychology, 67, 910-925.

Tugade, M. M., \& Fredrickson, B. L. (2007). Regulation of positive emotions: Emotion regulation strategies that promote resilience. Journal of Happiness Studies, 8, 311-333.

Walden, T. A., \& Smith, M. C. (1997). Emotion regulation. Motivation and Emotion, 21, 7-25.

Wegener, D. T., \& Petty, R. E. (1994). Mood management across affective states: The hedonic contingency hypothesis. Journal of Personality and Social Psychology, 66, 1034-1048. 